\title{
FORMAS DE AUTORÍA EN LA PERSECUCIÓN DE CRÍMENES INTERNACIONALES*
}

\author{
Jaime Alberto Sandoval Mesa**
}

Fecha de recepción: 5 de agosto de 2016

Fecha de evaluación: 12 de octubre de 2016

Fecha de aprobación: 21 de marzo de 2017

Artículo de reflexión

DOI: http://dx.doi.org/10.18359/prole.3038

Forma de citación: Sandoval, J. (2017). Formas de autoría en la persecución de crímenes internacionales. Revista Prolegómenos Derechos y Valores, 20, 40, 11-26. DOI: http://dx.doi.org/10.18359/prole.3038

\section{Resumen}

El presente artículo tiene por objeto indagar sobre las diversas formas de autoría en el orden internacional y su aplicación en la persecución de crímenes internacionales en el derecho interno. Este aspecto se viene presentando en los diversos precedentes nacionales mediante el alcance de la interpretación de precedentes de instancias de la justicia internacional. Dicha interpretación amplía las bases del derecho interno generando problemas de definición en un aspecto concreto como la autoría para tales casos, lo cual incide en la responsabilidad penal. Para los fines correspondientes, este documento se desarrolla según el método de investigación dogmático-jurídico y de análisis jurisprudencial, con uso de herramientas metodológicas, históricas, descriptivas, comparativas y propositivas.

\section{Palabras clave:}

Autoría, empresa criminal conjunta, dominio funcional, aparatos criminales, estructuras organizadas, superior jerárquico.

Artículo resultado de investigación del proyecto Der 1504 denominado "Aplicación de los criterios de la justicia internacional sobre autoría y participación en el caso de los fenómenos macrocriminales de derecho penal interno", Grupo de Derecho Público - línea de derecho penal del Centro de Investigaciones de la Facultad de Derecho de la Universidad Militar Nueva Granada.

* Ph.D. en Derecho, magíster en Derecho Penal. Profesor investigador, Universidad Militar Nueva Granada (Bogotá, Colombia). Correo electrónico: jaime.sandoval@unimilitar.edu.co 


\title{
TYPES OF AUTHORSHIP IN THE INTERNATIONAL CRIMES PROSECUTION
}

\begin{abstract}
Summary
The objective of this article is to investigate about the diverse types of authorship in the international order and its enforcement in the prosecution of international crimes under domestic law. This aspect has been presented in different national precedents by the grasp of the interpretation of previous instances of the international justice. Such an interpretation broadens the foundations of domestic law, creating concerns of definition in a concrete aspect, such as the authorship in those cases, which impairs the criminal liability. For the relevant purposes, the following article is developed under both the legal dogmatic and jurisprudential analysis method, using methodologic, historic, descriptive, comparative and propositional tools.
\end{abstract}

\section{Keywords:}

Authorship, joint criminal enterprise, functional domain, criminal apparatus, organized structures, superior.

\section{FORMAS DE AUTORIA NA PERSEGUIÇÃO DE CRIMES INTERNACIONAIS}

\section{Resumo}

O presente artigo tem como objeto pesquisar sobre as várias formas de autoria na ordem internacional e sua aplicação na persecução de crimes internacionais no Direito Interno. Este aspecto vem-se apresentando em nos vários precedentes nacionais através do alcance da interpretação de precedentes de instâncias da justiça internacional. Esta interpretação estende as bases do direito interno gerando problemas de definição em um aspecto concreto, como a autoria para tais casos, o qual incide na responsabilidade penal. Para os fins correspondentes, este trabalho é realizado sob o método de pesquisa dogmático-jurídica e de análise jurisprudencial usando ferramentas metodológicas, históricas, descritivas, comparativas e de propostas.

\section{Palavras-chave:}

Autoria, empresa criminosa conjunta, domínio funcional, aparelhos criminais, estruturas organizadas, superior hierárquico.

\section{Introducción}

El punto central de la autoría y la participación en estructuras organizadas de tipo criminal, es respuesta a las limitaciones de las figuras dogmáticas concebidas en la ley penal que tiende a tener preocupación por el asunto. Se identifica primero frente al contexto histórico de los ámbitos interno e internacional mediante diversas clases de respuesta para señalar a los máximos responsables. Esto significa que independiente del desarrollo penal existen y han existido.
Teniendo en cuenta esta naturaleza real de estructuras criminales que perviven en la sociedad, el objeto del presente estudio se centra en determinar si las fórmulas mucho más abiertas y generales, que son esbozadas en los precedentes de instancias internacionales, se pueden aplicar en casos de actualidad, en el derecho penal nacional, con respecto a la persecución de crímenes internacionales que se comenten en el escenario interno. 
En el momento, tal ejercicio suscita diversos problemas de interpretación, más allá de la permanente influencia en los actos objeto de juzgamiento, materialización y persecución efectiva como factor de determinación y sanción penal. Para los propósitos correspondientes se hace necesario, siguiendo el método elegido, indagar en una primera parte, por el contexto que da lugar al origen de aparatos organizados de poder en el derecho interno nacional, atendiendo sus elementos históricos.

Luego se examinan los antecedentes de las figuras empleadas en casos de estructuras macrocriminales y por último los casos especiales que han sido objeto de investigación y juzgamiento en el derecho interno, mediante elementos propositivos y descriptivos junto con el análisis jurisprudencial. Al final se tratará de evidenciar si los alcances de las decisiones judiciales actuales avanzan a consideraciones más amplias de la autoría y si es posible prescindir de la responsabilidad del instrumento así sea fungible o si por el contrario se trata de una evolución teórica mas no práctica.

\section{A. El contexto de los aparatos organizados de poder y su persecución}

En la historia nacional se puede identificar situaciones asociadas a elementos generadores de aparatos criminales organizados de poder. $\mathrm{Mu}-$ chas de las violaciones a derechos humanos que comenzaron a configurar conductas criminales en virtud de la aplicación de normas de excepción, en forma paralela al estatuto punitivo (decreto 1923 de 6 de septiembre de 1978), tuvieron el suficiente alcance para actuar dentro de un contexto similar a lo que Claus Roxin $(2000,2006)$ denomina una organización dentro del Estado, al margen del derecho, capaz de tener hombres de atrás que ordenan delitos con mando autónomo, sobre unos ejecutores también responsables.

En efecto, a pesar de los avances en este tiempo, sobre todo con la expedición del decreto-ley 100/1980 (Código Penal) que desarrollaba la dogmática penal que contemplaba la figura del autor mediato, las prácticas oficiales rebasaban el ámbito de protección del estatuto punitivo. Por ende, esto se reflejaba en los ciudadanos, dado que las facultades en la normativa citada, reprimían actos relacionados con las manifestaciones de protesta, distribución de documentos que pudiesen ser considerados subversivos, etc.

Esto por supuesto obedecía a la competencia asignada a comandantes de brigadas militares, incluso por delitos menores (Iturralde, 2010). Todo este escenario jurídico y fáctico era propicio para la generación de atentados provocados por estructuras criminales, bien dentro del Estado o fuera de él, que comenzaban a aparecer en las transgresiones punitivas de la época, en Colombia, según características que revelaban organizaciones con una identidad independiente de la propia de sus miembros (Roxin, 2000), como por ejemplo, en las organizaciones subversivas o paraestatales que se avizoran en este tiempo.

Las disposiciones del decreto 1923/1978 (Estatuto de Seguridad) permitían proceder en forma aparente, al amparo del derecho, pero a su vez, al margen del derecho, como otra de las particularidades de las estructuras organizadas de poder (Roxin, 2000). En este caso, puede que el estatuto en mención menoscabara libertades, pero órdenes de desaparición forzada o tortura no se encontraban dentro de sus cauces jurídicos, por ello vale resaltar que las actuaciones sobre comisiones de delitos no están al amparo del derecho sino por fuera de él.

En este sentido, el informe de la Comisión Nacional de Reconciliación y Memoria Histórica señaló que las normas de excepción indicaban cuerpo doctrinario y normativo (decreto 1923/1978) que instrumentalizó la doctrina de la seguridad nacional y el concepto de enemigo interno, con cualquier adversario que operara en la nación. Si bien la Corte Suprema de Justicia (CSJ) declaró algunos artículos como inexequibles, del estatuto en cita, este factor de contexto sirvió de base para los avances de las guerrillas y sobre todo la popularidad del M-19. 
En vigencia del estatuto (1978-1982) se produjeron 82000 detenciones arbitrarias y torturas en guarniciones militares contra miembros de guerrillas como EPL y ELN y otros grupos de izquierda, estudiantes de universidades públicas, etc. Todo ello como consta en el informe de la Comisión Interamericana de Derechos Humanos (OEA/SER.I./V/II) de 1981 (Grupo de Memoria Histórica, 2014).

Por lo anterior, el decreto es calificado como uno de los fundamentos para las prácticas ilegales de los agentes estatales y de estructuras organizadas de poder cuyas actuaciones se traducían en conductas como la desaparición forzada, la tortura y otros tratos crueles inhumanos y degradantes. En esta época los gobiernos fueron calificados como militaristas (Julio César Turbay Ayala, 1978-1982), lo cual implicaba no solo una respuesta coyuntural a un conflicto en crecimiento sino a medidas que propiciaron actos de agentes estatales por fuera de la legalidad (Grupo de Memoria Histórica, 2014).

Frente a este panorama, el código de 1980 concibió una estructura dogmática que, a pesar de todo, sirvió como soporte para evitar la consolidación de estas figuras de excepción y de algún modo rescató la posibilidad de crear medidas especiales para identificar actores que tuviesen un comportamiento en la forma especial de la autoría mediata (Pérez, 2009).

Sin embargo, todavía no se observa la persecución de los aparatos organizados de poder, esto solamente se va a identificar con el tiempo, luego de las graves violaciones de derechos humanos que se gestaron durante los años ochenta y que sirvieron de fuente para la conformación de una estructura paralela que fue el germen de un nuevo tipo de criminalidad mayor.

En este sentido, se debate en la actualidad si eventos como los anteriores corresponden a grupos ilegales dentro del mismo Estado y a estructuras organizadas de poder, las cuales se consideran que obran al margen del Estado (Corte Suprema de Justicia, sentencia de 16 de diciembre de 2015, rad. 38957). La diferencia es relevante en tanto que se extiende el radio de operación de la autoría y la participación penal, con la consecuente persecución del delito, tomando en cuenta las órdenes del superior jerárquico sobre un aparato fungible o intercambiable, que además no le resta importancia en la tarea de atribuir a los máximos responsables la comisión de delitos.

Por ejemplo, en asuntos como el del Palacio de Justicia de Colombia, en la primera instancia del tribunal se atribuye la presencia de estructuras organizadas al margen de la ley y después en la sentencia de casación, la CSJ determinó que no había suficiente material probatorio para establecer los elementos que supusieran la existencia de la estructura en estudio (Corte Suprema de Justicia, sentencia de 16 de diciembre de 2015, rad. 38957).

En todo caso, este tipo de criminalidad aparece en otros contextos como en el sistema interamericano (caso Los 19 comerciantes us. Colombia; La Rochela vs. Colombia, entre otros), en los cuales se revelan algunas de sus características: organización que puede estimarse como una entidad nueva y que distingue a efectos de la imputación de responsabilidad penal, las personas físicas que emplean el sistema criminal como herramienta de la organización criminal en sí (Roxin, 2000).

De acuerdo con Caro (2014), se trata de una estructura compleja de carácter esencialmente delictivo. En la misma concurren y conviven el mando y los subordinados, quienes deberán obedecer incluso órdenes de asesinato.

La siguiente sección estudiará la correlación entre los desarrollos en este aspecto de las actuaciones penales internas y la persecución de tales aparatos criminales, todo ello respecto de los precedentes internacionales y la perspectiva que puede generarse en virtud de los avances modernos en el tema. 


\section{B. Persecución penal internacional de crímenes internacionales}

La autoría y participación en el contexto de la responsabilidad del superior jerárquico, son materia de debate que incluso discute formas de imputación internacional. La corriente dogmática tradicional contemporánea concibe la autoría y en concreto la autoría mediata, como la actuación de un auténtico autor que utiliza a otro como instrumento para cometer el delito, que en últimas es obra suya, dado que ha existido dominio de la voluntad. Esto con el apoyo del animus auctoris con el cual se puede atribuir fácilmente la voluntad del autor al sujeto de atrás (Roxin, 2000).

Desde este punto de vista el autor mediato -hombre de atrás- no lleva directamente las conductas prohibidas, sino que se vale de otro como instrumento (Ferré, Núñez y Ramírez, 2010). Para Roxin (2000) esta teoría subjetiva apunta a quienes mueven los hilos de una organización: los inductores, aunque esto puede no ser un criterio útil para diferenciar al autor mediato del inductor. Este primer cuestionamiento conlleva indagar acerca de la autoría mediata en el seno de grandes organizaciones criminales constituidas por aparatos organizados de poder.

Por otra parte, este tipo de autoría mediata se despliega en virtud de coacción, en la cual, el coaccionado debe actuar amparado de una causal de justificación (estado de necesidad justificante artículo $32.7 \mathrm{CP}$ ), en este sentido, el dominio de voluntad se presenta por error vencible o invencible o en error de prohibición, o también en el caso del dominio de la voluntad mediante la utilización de inimputables y menores (Ferré et al., 2010).

Entonces, ¿qué sucede cuando no se dan estas variables, sino que el dominio del hecho se soporta en una estructura, es decir, en el marco de una organización? Esta pregunta no se apoya en situaciones de criminalidad ordinaria, sino en circunstancias que pueden identificarse en graves crímenes, como violaciones del derecho internacional de los derechos humanos (DIDH), que revelan ciertas obligaciones frente al superior jerárquico. Dichos elementos pueden servir de fuente para la concepción y persecución de fenómenos macrocriminales basados en esta clase de delitos de organización.

Desde las cuatro concepciones del dominio del hecho, se constata que frente a este problema los conceptos finalista y objetivo-subjetivo del dominio final, niegan el dominio del hecho macrocriminal en el marco de la organización jerárquica de un sistema conformado por individuos que mandan en la misma. Esta postura no se acepta debido a la valoración del hecho colectivo, perpetrado en la organización por individuos que están en los niveles inferiores de la jerarquía, considerados por el derecho penal como libres y por lo tanto responsables como autores (Simon, 2014).

Así, las formas de autoría en delitos de grandes organizaciones criminales se establecían en un principio a partir de la responsabilidad del superior jerárquico (Ramelli, 2011), a través del cual, se pudo identificar un concepto denominado macrocriminalidad como punto de partida para imputar responsabilidad penal.

Sobre este aspecto se han desarrollado diversas teorías producto de las investigaciones y precedentes originados en los tribunales internacionales que se advierten principalmente en los aparatos y grupos criminales que actúan en contextos de graves y masivas violaciones de derechos humanos (Aponte, 2011).

El esquema propuesto, al abrir esta base fáctica para extenderla a otros autores sustituibles o partícipes de la empresa criminal común, trata de plantear la posibilidad de imputar a los dirigentes y superiores de grupos armados con posiciones privilegiadas frente a la ejecución y puesta en marcha de políticas militares que afectaban a la población civil en graves infracciones al derecho internacional humanitario (DIH) o al DIDH.

En la tesis de Roxin (2006) se denominan delincuentes de escritorio, como en el caso del 
proceso contra Adolf Eichmann o la sentencia contra los miembros del Consejo de Seguridad Nacional del Gobierno de la Alemania del Este que en 1994 los condenó como autores mediatos de homicidios dolosos, porque habían ordenado a fugitivos que querían traspasar el muro de Berlín mediante disparos mortales.

Además de la tesis de Roxin (2006) se han sugerido en los tribunales internacionales otras teorías que obedecen no necesariamente a un concepto de acción dogmático penal, de tipo continental sino en muchos casos, a los precedentes que aparecen tanto en normativas internacionales como en los contextos propios de la justicia internacional, que acepta en mayor medida este tipo de imputación colectiva, a diferencia de la imputación individual propia de nuestro sistema interno de derecho penal.

Por otro lado, la praxis de los grupos de criminalidad en mención, implica la existencia de una posición jerarquizada que se cimienta en la división de trabajo, en la cual se puede advertir, un primer conjunto de personas responsables de las cuestiones estratégicas y otro dispuesto para la realización material de las decisiones. Según estos factores, los ejecutores o instrumentos no son coautores, pues falta la ejecución exigida en materia penal, ya que una instrucción y su observancia no son una determinación común para la comisión del hecho (Roxin, 2006).

En este caso, se establecen relaciones entre los grupos armados que actúan con base en órdenes generales coordinadas por superiores y otras derivadas del obedecimiento de lineamientos de actuación de tales grupos, lo que a su turno ha generado a lo largo de la historia, crímenes y violaciones objeto de persecución internacional. Incluso esta conformación está más fácilmente identificada en las normas del DIH que en el derecho penal.

Lo anterior comportó la investigación en tribunales nacionales e internacionales de los precedentes que surgieron al respecto y que se analizan a continuación sobre la responsabilidad del su- perior desde otros elementos jurídicos distintos de la dogmática penal tradicional. Más adelante se volverá sobre los argumentos aducidos por Roxin, como centro de la presente discusión.

\section{El denominado "Estándar Yamashita"}

El 19 de enero de 1946, el general MacArthur, supremo comandante de las potencias aliadas dispuso instaurar un tribunal especial para juzgar los crímenes de guerra del ejército japonés a raíz de los acuerdos de Potsdam. El tribunal tendría a cargo juzgar a las personas responsables de crímenes clase $\mathrm{A}$ (crímenes contra la paz), clase $\mathrm{B}$ (crímenes de guerra) y clase $\mathrm{C}$ (crímenes contra la humanidad), tal y como se desarrolló en Núremberg (Prieto, 2005). El mismo tuvo la representación de Estados Unidos y de once Estados.

Además de las actuaciones iniciadas y de la influencia del general MacArthur, fue de particular interés el fallo proferido por el tribunal en contra del general Tomoyuki Yamashita por crímenes de guerra cometidos por sus subordinados en las islas Filipinas (Bassiouni, 1999). El cargo imputado se dirigió a demostrar la actuación del general según la cual, se hizo caso omiso en su deber como comandante de la Armada 14 del Ejército Imperial Japonés y gobernador militar de las islas Filipinas (1944-1945). En su condición era de su competencia controlar las operaciones de los miembros que estaban bajo su mando. Así se les permitió cometer atrocidades brutales u otros delitos contra el pueblo de los Estados Unidos, sus aliados y dependencias (Aponte, 2011).

La defensa argumentó que se había producido la violación de la Convención de Viena y la Constitución Política de los Estados Unidos, por no haber participado directamente en la comisión de los delitos. Esta tesis se contrapuso con la normativa internacional existente en el momento, que indicaba ciertos elementos como el fundamento originado de la Convención de La Haya de 1907 sobre la responsabilidad de los superiores jerárquicos dentro de la estructura militar (anexo cuarto, artículos 1 y 43). 
En este caso, una de las condiciones para que se reconozca el estatus de beligerante es la existencia de un superior, de un responsable de las acciones de sus subalternos. El comandante debe tomar todas las medidas necesarias para restaurar y asegurar el orden público y el cumplimento de las leyes que rigen el país (Aponte, 2011).

Frente a esto, la Corte Suprema de Estados Unidos que conoció la apelación, indicó que independientemente de que el superior jerárquico participe de forma directa o no de las operaciones militares, que dé o no la orden de cometer un delito es responsable, dada su obligación de supervisión y control que tiene por el cargo que ostenta en la estructura de la organización militar.

En general, la postura sobre este aspecto se consignó en el Protocolo I Adicional a los convenios de Ginebra de 1949. Así se determina la responsabilidad de los superiores por el actuar de sus tropas. En estos casos el protocolo limita la responsabilidad del superior, en cuanto solo es responsable cuando conozca o posea información de la comisión del ilícito.

En el Estatuto de Roma de la Corte Penal Internacional (1998) se reflexiona sobre la responsabilidad del superior jerárquico, concretamente en el artículo 28 frente a dos supuestos fácticos según los cuales el superior jerárquico es responsable:

- Cuando el ilícito lo llevan a cabo fuerzas bajo su comando.

- Cuando se consume el delito por parte de sus subordinados.

El estatuto así reconoce que se puede ser responsable por acción o por omisión frente a las actuaciones que deriven en crímenes internacionales y, por lo tanto, se incorpora el Estándar Yamashita como el deber de conocer el actuar de las fuerzas que controla el superior jerárquico.

\section{Teorías de imputación de responsabilidad penal: la teoría de la joint criminal enterprise}

Alrededor de los argumentos anteriores se gestaron diversas teorías de la imputación en estructuras organizadas de tipo criminal, como por ejemplo la tesis que propuso el Tribunal Penal Internacional para la ex-Yugoslavia (caso Prosecutor vs. Duško Tadic). En este caso, se reconoce que los crímenes cometidos en el ámbito internacional, son manifestaciones de criminalidad colectiva o crímenes llevados a cabo por un grupo de individuos que actúa según un diseño criminal común (Aponte, 2011).

Para tal efecto, es importante destacar el escenario jurídico en el cual se presenta el análisis de contexto de la antigua Yugoslavia: se trata de un conflicto armado, que se evidencia cada vez que se recurre a la fuerza armada entre Estados o entre las autoridades gubernamentales y grupos organizados o entre tales grupos en el seno del Estado (caso Prosecutor vs. Duško Tadic). Es decir, se trató de grupos organizados de tipo militar y de fuerzas estatales, concepto que no es distinto de las estructuras organizadas de poder criminal.

Lo anterior se prueba en este caso, en que al momento de la comisión de delitos, hubo una división de tareas propia de las diferentes formas de coautoría que conducen a que en la práctica, solo un número pequeño de personas ejecute el delito (autores materiales), mientras que otro número de sujetos realiza acciones para facilitar y contribuir a su comisión como en el caso de los coautores (Aponte, 2011). Se da entonces la unión en torno al plan o empresa criminal común como fundamento de la teoría, de suerte que las personas que cometen el delito se unen gracias a ese plan común.

De igual forma, la participación voluntaria de los involucrados gira alrededor del objetivo común que debe ser ilícito o ilegal. La doctrina de la empresa criminal también exige que luego del acuerdo inicial, se ejecute el propósito criminal 
común, esto es, se exterioricen sus actos, como elemento que permite distinguir la joint criminal enterprise de la conspiración que solo supone la membresía al grupo como cimiento de la imputación (Aponte, 2011).

Así mismo, el elemento esencial de la empresa criminal común, es que se comparta el fin común y que el sujeto contribuya o facilite la comisión del ilícito. De esto se trata el elemento subjetivo y para ello es cardinal para que tenga aplicación la teoría, que cada uno de los individuos implicados contribuya en la ejecución del propósito común, con dolo directo, con la aspiración de que se consuman los resultados propios de la empresa criminal.

En efecto, se exige que el sujeto participe de forma dolosa en la realización del plan común. No necesariamente el sujeto debe ser el autor de la conducta, basta que contribuya y asista a la ejecución del propósito común, para que se entienda que fue coautor de los ilícitos cometidos. En síntesis, en el aspecto subjetivo se requiere que el sujeto comparta el fin colectivo y aporte con dolo directo a la consumación de los delitos materia del plan común.

También se presenta una posible extensión de la responsabilidad penal, toda vez que se pueden sancionar dos tipos de actores. A los que si bien, no han cometido crímenes graves, son responsables por pertenecer y compartir la empresa criminal común. Los líderes (militares y políticos) que habrían planeado la empresa común. Por otra parte, el Tribunal Penal Internacional para la ex-Yugoslavia reconoce tres formas de empresa criminal común (Aponte, 2011):

Primera: todos los participantes del propósito común, poseen la misma intención criminal de cometer un delito. Se exige: un propósito común (elemento subjetivo), la necesidad de que los asociados ejecuten cualquier tipo de acción tendiente a facilitar el delito.

Segunda: se conoce el hecho y se secunda el propósito general. Se debe cumplir una tarea tendiente a facilitar o impulsar el sistema organizado o sistematizado del maltrato.

Tercera: solo se aplica la noción de propósito común cuando se cumplan los siguientes requisitos del elemento subjetivo: la intención de tomar parte en la empresa criminal común y continuar el propósito criminal de la empresa. La previsibilidad de la posible comisión por otros miembros del grupo de delitos que no son el objeto del propósito criminal común (caso Prosecutor vs. Duško Tadic).

Solo se pueden cuestionar hechos que escapan de la naturaleza de la imprevisión, como por ejemplo actos individuales de los actores que no desarrollan la empresa criminal común. Además, es un concepto demasiado general para imputar responsabilidad y puede resultar indeterminado.

De igual modo, dado el fundamento dogmático y la tradición penal interna, sigue siendo demasiado amplio para asignar el concepto de participación para imputar responsabilidad. Se debe tomar en cuenta que el sentido de exteriorización de los actos, resuelve múltiples aspectos del concepto de acto penal, lo cual es relevante para los fines del presente trabajo.

\section{Teoría de coautoría basada en el joint control over the crime}

Claus Roxin (2000) sostiene que existen situaciones en las que surgen límites entre el dominio de la acción y el dominio de la voluntad. En este espacio, el agente no tiene dominio ni de la una ni de la otra $y$, sin embargo, participa activamente en la realización del delito. Por lo tanto, cabe plantear su autoría, aunque la acción típica la lleve a cabo otro partícipe. Se trata de un aspecto donde en caso de que a una persona se le impute un delito a título de coautor, no es menester que haya perpetuado físicamente el delito, sino que su coautoría se deduce del control efectivo que el sujeto tenga o haya tenido sobre la comisión del delito (Ferré et al., 2010). 
De acuerdo con estos supuestos se resalta la posición clave de cada interviniente en la ejecución de la conducta, frente al tipo de acciones, en lo que Roxin (2000) llama la cooperación en la fase ejecutiva y la cooperación en la fase de ejecución. No obstante, el asunto significativo se deriva de la debida intervención que pueda otorgarle al agente, el rol de coautor y para ello es necesario revisar su aportación para ostentar el dominio del hecho.

Al respecto Roxin (2000) admite que algunos niegan esta noción, puesto que uno solo puede ser responsable de su parte y no del hecho global, postura última sobre la que se asienta el dominio funcional. Frente a este punto se define la controversia en que no hay contradicción, pues cada individuo domina el acontecer global en cooperación con los demás, lo cual implica que el coautor no tiene el dominio del hecho por sí solo, pero tampoco ejerce un dominio parcial, sino que el dominio completo reside en varios que pueden actuar en forma conjunta. Se tiene en cada uno de ellos el destino del hecho global.

Por ejemplo, en aquellas en las que se deduzca la no participación por separado de los intervinientes, se puede anular el plan común. Así las acciones son claves y cada autor tiene la capacidad de impedir la comisión del delito (Aponte, 2011).

El interviniente no puede ejecutar nada solo, por ello se denomina dominio funcional que corresponde al dominio como forma de autonomía del dominio del hecho. Por ejemplo, la intimidación de los empleados del banco o el sujetar a la víctima, no realizan el resultado, únicamente esto se produce si cada uno coopera, puede ejecutar el plan conjuntamente. El desarrollo de cada uno por separado puede anular el plan conjunto retirando su aportación (Aponte, 2011; Roxin, 2000). A través de esta valoración se evidencia la posición clave de cada interviniente y se describe con exactitud la estructura de la coautoría. Por ende, la idea básica de la coautoría, siempre que se conciba como un dominio del hecho conjunto (Roxin, 2000).
Por ejemplo, en el caso contra Thomas Lubanga, la Corte Penal Internacional (CPI) aplicó la teoría en su providencia del "domino del hecho" por el crimen internacional de reclutamiento de menores, al indicar que el acusado asumió un papel cardinal de coordinación general en la puesta en marcha del plan e igualmente cumplió personalmente funciones en su ejecución. La CPI al implementar la teoría de Roxin, sostuvo en relación con el elemento fundamental del codominio del hecho, que en la comisión de un delito concertado, ninguno de los sujetos que actúan (coautor) tiene control total del delito, pues depende de los otros para su comisión. Por ello, es coautor todo aquel que tenga la posibilidad de frustrar la comisión del ilícito, omitiendo su función dentro del grupo criminal. Solo si todos los coautores actúan en forma coordinada se produce la consumación del delito (Aponte, 2011).

Se exige además la participación de todos los sujetos para la consumación del hecho -así se concibe el efectivo control sobre el resultado del delito (over the crime)-. Ninguno de los que participan tiene el control total del delito, pues dependen unos de otros para su comisión; todos comparten el control, todos deben ejecutar su tarea para la consumación final del crimen (Roxin, 2000).

Por otra parte, frente a la clase de contribución en este tipo de autoría, la CPI desarrolló elementos para aplicar la teoría en forma más consistente, toda vez que el plan común debe incluir un elemento de criminalidad. En tal sentido, el mismo debe estar construido en torno a la posible omisión de un delito, independiente de que pueda hacerse realizable o no. Así el requisito del elemento criminal se encuentra satisfecho. También se entiende cumplido cuando los coautores son conscientes del riesgo de la aplicación del plan común, el cual se traduce en la comisión de un delito y la aceptación de su resultado -dolo eventual- (Aponte, 2011).

Además del plan común, debe existir una contribución esencial hecha de forma coordinada por 
cada uno de los coautores. Siendo esto así, tienen "dominio funcional del hecho" solo aquellos a los que se les ha asignado una tarea fundamental y quienes pueden frustrar la comisión del delito al ejecutar dicha tarea. Es decir, es coautor todo aquel cuyo aporte en la fase ejecutiva resulta indispensable para la realización del resultado previsto (Roxin, 2000). Solamente existe una excepción: si alguno actúa en forma independiente del plan para lograr otro resultado, este le pertenece y no puede subordinarse al plan global del grupo.

Así entonces, la diferencia entre la empresa criminal común y la teoría del dominio funcional implica que la primera no exige que la contribución del sujeto sea esencial, basta con que se realice una tarea de menor importancia pero que sea ejecutada con dolo respecto a la consumación del propósito criminal. En la teoría del dominio funcional demanda que la contribución sea vital, de tal suerte que la omisión de dicha contribución frustra la comisión del delito. Se trata de un concepto abierto mas no indeterminado y, por lo tanto, sus elementos de coautoría se pueden obtener mediante la subsunción y la valoración de complementación judicial, necesarias en estos casos (Roxin, 2000).

Ahora bien, en los delitos internacionales este tipo de coautoría solo puede servir para casos particulares, lo cual comporta que se pierde la revisión de los objetivos de una organización o estructura criminal, y por ende, sigue pendiente el examen de las actuaciones en delitos de organización mediados por el plan común. Es decir, esta modalidad persigue tradicionales estructuras de delincuencia, pero no macroestructuras criminales a las que se viene haciendo alusión.

\section{Autoría mediata a través de estructuras organizadas de poder. Análisis jurisprudenciales}

Respecto al tema que se plantea y sus efectos en el sistema nacional, se puede mencionar la aplicación de la fórmula de la autoría en el Código Penal de Colombia. En este caso, el sistema colombiano admite dos formas de autoría mediata: la coacción ajena y el engaño, formas que respetan el postulado contenido en el artículo 29 del CP.

En cuanto a la teoría de Roxin (2006), se observan varias diferencias, pues en la autoría mediata en estructuras de poder, el autor material determinado por el hombre de atrás, actúa plenamente responsable, sin embargo, es fungible o sustituible. Los ejecutores o instrumentos no son coautores, pues en la falta de ejecución en común -y en muchas ocasiones no se conoce el autor del mando central- no aparece una unión recíproca de cómplices que colaboran al mismo nivel y se excluye la inducción.

Se trata de un dominio de organización, existe una provocación al hecho, pero al contrario del inductor el hombre de atrás toma la decisión por existir un mando de poder, que es determinante para la ejecución. Por lo general el inductor se encuentra fuera de la organización, el hombre de atrás no, forma parte de ella (Roxin, 2006). De acuerdo con esto, la teoría impone sancionar con el más alto rigor a los mayores responsables, al superior jerárquico y no al miembro raso que puede ser sustituible (fungibilidad pura).

La Unidad de Derechos Humanos de la Fiscalía ha puesto en práctica en varios casos emblemáticos la tesis de Roxin en relación con la fungibilidad del autor, explicando que esta teoría se aplica a organizaciones (como las Farc) en las cuales, aquellos que conforman la cúpula confían en que sus órdenes se cumplan, sin que se tenga que conocer quién las ejecuta. Esto es, si uno de los miembros que participan en la comisión de los delitos no lo ejecuta, otro lo hará, sin que se afecte la ejecución global del plan.

Aquí faltan varios elementos, pues no solo se trata de identificar la organización y la existencia de un dominio del aparato de poder, sino también de verificar la pluralidad de personas que integran la estructura, nivel de cooperación y funciones relativas a la organización cuyo entramado asegura al hombre de atrás el dominio 
del resultado (Roxin, 2006). No solo se trata de la fungibilidad de sus miembros sino que la producción del resultado se ejecuta mediante la influencia del aparato organizado de poder. La seguridad de resultado fundamenta el dominio del hecho a diferencia del dominio de la acción del ejecutor (Roxin, 2006).

Estos detalles del dominio de la organización en esta primera decisión no se advierten, siendo un elemento medular, pues el mando, la actuación dirigida a cumplir con la organización o las acciones al margen del derecho, pueden ser identificadas, sin embargo, no se aprecia este aspecto. Nuevamente las fórmulas desde el derecho interno son insuficientes para determinar sobre todo este elemento, es decir, el valor ficticio de la organización y su capacidad de estructurar acciones y responsabilidades como cuerpo propio.

Por otro lado, la Sala Penal de la CSJ, aplicando fórmulas de imputación más acordes con la realidad de la comisión masiva de crímenes internacionales, ha visto como fórmula de coautoría impropia, que la misma no se ajusta a aparatos en los que participan centenares de personas en el trabajo criminal (Corte Suprema de Justicia, SCP. Rad. 23825. M. P. Javier Zapata. Coautoría impropia en la Cúpula del ELN-Caso Machuca).

En este caso, la Sala Penal de la CSJ en sentencia de 16 de septiembre de 2009 en relación con la responsabilidad de los superiores jerárquicos, hace referencia a los aparatos de poder o máquinas de guerra. Esto es, de nuevo se revela la existencia de los aparatos mencionados. Por ejemplo, analizó la aparición de los frentes "La Gabarra" y "Fronteras" del bloque Catatumbo de las autodefensas en Norte de Santander (Colombia) y su proceso de afectación a la sociedad dada la estructura criminal que se consolidó en este lugar.

Este punto es interesante, pues revela la existencia del poder de mando de los bloques en alusión que identifican los niveles de jerarquía, el personal ejecutor, el de servicio y los factores de ejecución. No obstante, en la misma solamente falta identificar quiénes en orden pueden ser autores mediatos tras otros autores mediatos y quiénes pueden tener un nivel de complicidad, conforme con las condiciones de la organización expuesta por Roxin (2006).

En el hecho fallado se narró el proceso de intimidación de la población civil y cómo después de que el grupo paramilitar citado aseguró el dominio político y territorial, logró la infiltración de la organización en la sociedad, a tal punto que recibió colaboración y participación del procesado en este caso, quien para esta época aspiró a la gobernación del departamento (Corte Suprema de Justicia, sentencia de 16 de septiembre de 2009. Rad. 29640, M. P. Julio E. Socha Salamanca). Este aspecto además de identificar la génesis del grupo y su estructura, todavía requiere de mayor identificación de las responsabilidades.

Lo relevante es que la providencia señala que se demostró la finalidad del procesado de promover un grupo armado al margen de la ley, pues no solo fue apoyado económicamente en sus proyectos políticos, sino que el aparato organizado de poder que encarnaba el paramilitarismo en Norte de Santander, fue puesto al servicio de esa causa, con el evidente propósito de que el político ejerciera el poder que aspiraba obtener al servicio del proyecto paramilitar.

Según la Corte este propósito se manifiesta en el concierto para promover aparatos organizados de poder ilegales (Corte Suprema de Justicia, sentencia de 16 de septiembre de 2009. Rad. 29640, M. P. Julio E. Socha Salamanca). Este elemento según la teoría de Roxin (2006) revela la desvinculación del aparato del ordenamiento jurídico, así actuara dentro de las estructuras estatales locales en este caso. A este punto se le puede adicionar que estas medidas son ilegítimas al margen del orden constitucional del Estado. Pueden ser legales, pero universalmente ilegítimas; es una actuación que no corresponde a un Estado de derecho. Este análisis se observa 
cuando indica que dicha valoración no se realiza sobre el anterior estatus político sino sobre la actual valoración jurídica.

De igual modo, en sentencia de febrero de 2010, la Corte avanzó en fórmulas de imputación de la responsabilidad al "superior jerárquico" y anotó diferentes formas de autoría que pueden tener lugar en un mismo sujeto activo. El actor como determinador (congresista Álvaro García - Instrumento responsable. Sentencia SCP. 23.02.2010. M. P. Leonidas Bustos). En esta sentencia relativa a la masacre de Macayepo se sanciona como autor mediato al político introduciendo un matiz, pues se afirma que el mismo obró con instrumentos responsables que hicieron las veces de ejecutores de los homicidios, no obstante, la calificación del delito en la condena señala al congresista como determinador.

En este caso frente a la teoría analizada, falla la denominación del autor, pues en principio lo identifica como autor mediato, pero luego lo condena como determinador, situación que se asimila más al inductor. Es decir, no realiza los fundamentos de la teoría en estudio. De igual manera, no se analiza el sistema de organización al que pertenecía el autor, pues en los aparatos organizados de poder, el sistema (el sistema parcial de un Estado) tiene que trabajar delictivamente como un todo (desvinculado del derecho), mediante el cual, la seguridad del resultado que fundamenta una autoría mediata, se atribuye a las instrucciones de los hombres de atrás (Roxin, 2006).

Así la Corte varía la jurisprudencia y apunta que la autoría mediata se presenta cuando una persona sin pacto tácito o expreso utiliza a otro como instrumento para que efectúe un delito. El hombre de atrás es el único responsable, porque la persona que es utilizada como instrumento, no realiza conducta o su conducta es atípica o concurre con una causal que lo exonera de responsabilidad. La Corte así, tiene como salida la noción de instrumento responsable, pero no sale de la responsabilidad del ejecutor material con base en la argumentación sobre coautoría impropia (congresista Álvaro García - Instrumento responsable. Sentencia SCP. 23.02.2010. M. P. Leonidas Bustos).

Como se puede observar, la jurisprudencia interna revela componentes de la teoría del dominio de la organización mediante la autoría mediata en aparatos organizados de poder, pero no aborda con profundidad sus elementos. Por el contrario, desemboca en la determinación y en el dominio de la acción o de la voluntad bajo formas de coautoría impropia o en la tesis de la autoría mediata, sin acometer el centro de la discusión, ni fijar los elementos susceptibles de responsabilidad en el caso de la teoría en análisis.

Otro aspecto que sigue pendiente tanto en la teoría de Roxin como en su aplicación interna, se advierte en la posibilidad de no encontrar a los ejecutores materiales, con respecto a la responsabilidad del superior jerárquico, mandos medios, y sancionarlos. El soporte político-criminal de la teoría de Roxin es hallar la persona que ha dado las órdenes generales, que ha dispuesto todo para la comisión de los delitos y en lo posible perseguir a los autores materiales. Al contrario de las fórmulas tradicionales de la autoría, en las que el fundamento aplicado es la cercanía del autor con el hecho consumado, en la teoría de Roxin es la lejanía del hombre de atrás de los hechos lo que sirve de fundamentación. Todo ello se puede construir a través del contexto en la investigación del hecho.

Si bien existe la posibilidad de sustituir a los ejecutores, en este caso puede suceder que el ejecutor fungible perdone a las víctimas y las deje escapar, esta crítica implica que, pese a todo, la voluntad sobre la acción la conserva el agente. Este es uno de los puntos centrales, pues la considerable elevada disponibilidad al hecho del ejecutor sigue siendo demasiado amplia frente al ámbito de discrecionalidad del mismo, en donde su voluntad sigue siendo libre de apremio. Roxin (2006) asevera que en todo caso si no lo ejecuta un actor lo hace otro, pues obedecen a los mandos de la organización. 
Por otro lado, es claro que Roxin admite que en casos de designación de un especialista, entra en consideración más bien la inducción, y que puede haber casos en los que el ejecutor no llegue a ejecutar el hecho. Esto no hace inviable la teoría, sino que la convierte en relativa al ampliarse a la exigencia de disposición del hecho (Ambos, 2011).

Uno de los casos emblemáticos sobre este asunto, corresponde a la Corte Suprema del Perú que dictó sentencia en su contra por asesinatos cometidos en su país, haciendo referencia a la teoría de Roxin. Sancionó las actuaciones del hombre de atrás en estructuras organizadas de poder y para tal efecto tomó los elementos característicos de la tesis como por ejemplo: la existencia de una organización a cargo del expresidente Fujimori, toda vez que el mismo detentó la posición del más alto nivel dentro de la organización estatal (hombre de atrás -poder decisorio-).

Esto le permitió tener poder de mando para la conducción directa de las estrategias de enfrentamiento contra las organizaciones subversivas terroristas (ejecutores responsables) y por ende, de la organización de la empresa estatal de tipo criminal (mando, organización y estructuras y disponibilidad a los crímenes de la organización). De igual forma, los miembros de las Fuerzas Armadas ligados a violaciones de derechos humanos y DIH, se concibieron como integrantes de un aparato ilícito, ilegal, de poder.

En cuanto a la fungibilidad de los autores materiales del delito, se apunta en la sentencia que su condición fungible, su disposición al hecho y su no relación directa con el acusado, permitieron afirmar la posición de Fujimori como autor mediato como ente central con poder jerárquico de dominio sobre el aparato de poder. En este caso se evidencia que todas las actuaciones se desarrollan dentro de un contexto indudable que señala la presencia de actores propios de una organización o estructura criminal o empresa criminal. Es de entender que se trató de un juicio con un alcance interno $e$ internacional que descubrió una amplia flexibilidad jurídica; esto en el caso comparado de Colombia todavía sigue sin tomar consistencia.

Para Kai Ambos (2011) hay que matizar el concepto de Roxin y perfeccionar la teoría del dominio de organización respecto al modelo de imputación mixto (individual-colectivo) del derecho penal internacional. Lo anterior ayuda a entender mejor la situación colombiana que vive justamente entre la imputación individual y la colectiva. En este sentido, al identificar la organización como tal, uno de los aspectos relevantes analizados aquí, destaca que en la teoría de Roxin existe una predisposición al hecho típico de la organización que resalta justamente el predominio frente al individuo de la propia organización. Es un dominio del hecho en términos colectivos y solo a través de la mediación de la organización sobre los miembros ejecutores del hecho (Ambos, 2011). De allí la necesidad de matizar la estructura analizada, para hacerla viable a conflictos como el nacional o el propio caso de Perú.

Es preciso además hacer claridad sobre este punto: Roxin acepta a las organizaciones criminales no estatales dentro del dominio de la organización, cuando actúan como un Estado dentro del mismo Estado, cuando las mismas presentan continuidad, con independencia del cambio de sus integrantes, donde cada miembro actúa como parte funcional de un todo, de cierto modo mecánico para la realización de un hecho (Ambos, 2011).

Ambos (2011) aduce que hace falta precisión del concepto de organización en los eventos en los que la misma consta de un número determinado de ejecutores como en el caso Fujimori, o por ejemplo de una organización militar no estatal como en el caso Katanga.

Kai Ambos (2011) propone para tal efecto, la distinción entre aparatos de poder organizados estatales y no estatales, dentro de estos últimos se adiciona la diferencia entre un aparato de poder formal y un grupo informal. En este 
caso considera posible tales elementos, en una organización jerárquica estructurada con un número elevado de ejecutores fungibles. Esto facilita diferenciarlas de las bandas comunes y sin organización.

Por ejemplo, en el caso Fujimori se advierte un dominio de la organización en el ámbito estatal (evento clásico), pero el verdadero aparato de poder organizado se despliega a partir de la mencionada estructura del servicio secreto de Perú. Se trata de un Estado dentro del mismo Estado, donde el denominado grupo Colina era su órgano ejecutivo militar. En estos casos es importante según Ambos (2011) no dejar tan amplio el radio de quienes pueden dar las órdenes sin que estas puedan ser retiradas, pues los coautores que a la vez reciben e imparten órdenes son coautores.

Otra situación indica que el primer fundamento que se puede identificar con esta teoría surge de los precedentes internacionales que tratan la sanción por omisión como tendencia actual de las fórmulas de imputación de responsabilidad. Con esta orientación se ha acogido en los contextos internacional y nacional el desarrollo de la omisión como criterio de imputación del superior jerárquico. De acuerdo con ello, la CSJ ha sancionado a miembros de las Fuerzas Armadas por delitos cometidos por grupos ilegales que actuaron en territorios bajo su comando o han obrado con su aquiescencia, con base en la omisión y en la figura de la posición garante, por omisión impropia (Corte Suprema de Justicia, sentencia SCP. Rad. 24448. 12.09.2007, M. P. Augusto Ibáñez).

En este sentido, la omisión frente al superior jerárquico implica la conexión dogmática en función de la imputación como por ejemplo en casos de la CSJ en los denominados "falsos positivos". En estos asuntos se denuncia crímenes cometidos contra civiles desarmados haciéndolos pasar por muertes en combate, lo cual es objeto de comprobación por parte de la Corte, al indicar que no se trata de autores materiales aislados, dirigiendo su atención al superior jerárquico, sino que se ejerce un plan común (Corte Suprema de Justicia, SCP., sentencia 21.10.2009. Rad. 25682, M. P. Yesid Ramírez Bastidas).

No obstante, lo anterior difiere de la teoría del dominio funcional en aparatos organizados de poder y se orienta más a identificar la cadena de mando -para hallar responsabilidades individuales- que a detectar la existencia de una organización en los términos en mención.

En resumen, el concepto de organización de la teoría del dominio de la organización, con relación a grupos paramilitares o subversivos no estatales en conflictos armados, como la situación nacional, tiene que continuar ampliándose y desarrollándose más allá de su comprensión inicial, que algunos identifican como de burocrático-estatal formal, en la primera versión de Roxin. Todo ello por cuanto el dominio se basa en factores informales que resultan del entorno y actuar sociocultural (Ambos, 2011). A este punto vale la pena explorar para dar solidez a la teoría, sobre todo en conflictos armados, los elementos y exigencias de las organizaciones disidentes no estatales que aparecen en los instrumentos del DIH.

En este caso el enlace que reclama Kai Ambos entre la teoría dogmática de imputación individual y la teoría colectiva de imputación que internacionalmente se desarrolla en otros ámbitos puede coexistir con la integración normativa interna e internacional. Todo ello para evitar imputaciones generales que en alguna medida se consignan en la teoría de Roxin.

\section{Conclusiones}

Si bien en el plano internacional se avanza en la consideración de formas actuales de participación denominadas estructuras de poder organizadas o macrocriminalidad, su persecución interna todavía adolece de elementos que puedan extender la responsabilidad destinada a identificar a los máximos responsables de las mismas, prescindiendo de los rangos inferiores bajo la consideración de su fungibilidad. 
A lo sumo se puede verificar la existencia de organizaciones de esta índole en la realidad penal interna, sin embargo, su identificación como estructura con miembros fungibles no perseguibles y otros de poder y mando perfectamente imputables, aún descansa en decisiones desde la óptica del instrumento responsable en el ámbito punitivo.

En virtud del DIH y demás instrumentos del DIDH y de regulación de los conflictos armados, se señalan precisas reglas para la conformación de los grupos armados organizados a los cuales se hace referencia. Tales instrumentos podrían dar lugar a los niveles y estructuras que por lo general se presentan en organizaciones similares, tales como los grupos subversivos y paramilitares que participan en estos conflictos frente a fuerzas estatales.

Sobre esto, es posible adaptar la organización, si presenta la teoría de Roxin, además de los lineamientos generales de precisión de Kai Ambos. No obstante, al investigar el seno de cada organización, seguramente su estructura, sus funciones y aspectos detallados de configuración, van a descender en diferencias ostensibles entre muchas de ellas. Lo relevante es que conciban los marcos globales trazados por Roxin o aun los detalles especiales de Ambos, pero de acuerdo con la sociología de cada organización, de seguro cada una va a conservar diferencias especiales del tipo de organización, mando y disposición al hecho.

En todo caso, la teoría de los aparatos organizados si bien tiene elementos que se pueden identificar en las organizaciones en estudio, y así lo ha realizado la jurisprudencia nacional, de acuerdo con las reglas de imputación penal que rigen en Colombia, todavía no admite la autoría mediata de un autor para crímenes generales sin la presencia del instrumento, responsable o no y menos admite su fungibilidad. Si bien se han hecho avances en algunos de los factores que identifican a las estructuras organizadas de poder en Colombia, aún está pendiente su asunción completa. Todavía no bastan ni siquiera los elementos matizados propuestos por Kai Ambos conforme con lo expuesto aquí.

\section{Referencias}

Ambos, K. (2011). Sobre la organización en el dominio de la organización. Revista Indret, 3.

Aponte, A. (2011). Persecución penal de crímenes internacionales (diálogo abierto entre la tradición nacional y el desarrollo internacional). Bogotá: Pontificia Universidad Javeriana, Fundación Konrad Adenauer Stiftung, Grupo Editorial Ibáñez.

Bassiouni, M. C. (1999). De Versalles a Ruanda en 75 años: la necesidad de establecer una corte penal internacional permanente. Revista de Derecho Público, 10, pp. 45-103.

Caro, J. J. (2014). La autoría delictiva del expresidente Alberto Fujimori Fujimori. XXXV Jornadas internacionales de derecho penal. Procesos de paz. Derecho penal y justicia transicional. Bogotá: Universidad Externado de Colombia.

Corte Suprema de Justicia, Sala de Casación Penal. (2009). Sentencia de 16 de septiembre. Rad. 29640 M. P. Julio E. Socha Salamanca.

Corte Suprema de Justicia, Sala de Casación Penal. (2009). Sentencia de 21 de octubre de 2009. Rad. 25682. M. P. Yesid Ramírez Bastidas.

Corte Suprema de Justicia, Sala de Casación Penal. (2010). Congresista Álvaro García - Instrumento responsable. Sentencia de 23 de febrero. M. P. Leonidas Bustos.

Corte Suprema de Justicia, Sala de Casación Penal. (2007). Rad. 23825. M. P. Javier Zapata. Coautoría impropia en la Cúpula del ELN-Caso Machuca.

Corte Suprema de Justicia, Sala de Casación Penal. (2007). Sentencia de 12 de septiembre. Rad. 24448. M. P. Augusto Ibáñez. 
Corte Suprema de Justicia, Sala de Casación Penal. (2015). Sentencia de 16 de diciembre. Rad. 38957. M. P. Luis Guillermo Salazar Otero.

Decreto 1923. (1978). De 6 de septiembre. Diario Oficial 35101 de 21 de septiembre de 1978.

Ferré, J. C., Núñez, M. A. \& Ramírez, P. A. (2010). Derecho penal colombiano. Parte general. Principios fundamentales y sistema. Bogotá: Grupo Editorial Ibáñez.

Grupo de Memoria Histórica. (2014). Informe Basta Ya. Bogotá: Centro Nacional de Memoria Histórica de la República de Colombia, Editorial Departamento de la Presidencia de la República, Embajada de Suiza.

Iturralde, M. (2010). Castigo, liberalismo autoritario y justicia penal de excepción. Bogotá: Siglo del Hombre Editores, Universidad de los Andes, Pontificia Universidad Javeriana, Instituto Pensar.

Pérez, Á. O. (2009). Introducción al derecho penal. Bogotá: Temis.

Prieto, R. A. (2005). La internacionalización de la jurisdicción penal. De Versalles a Bagdad. Bogotá: Biblioteca Jurídica Dike.
Caso Prosecutor vs. Duško Tadic. (s. f.). Case No.: IT-94-1-D, decision of the trial chamber on the application by the Prosecutor for a formal request for deferral, 8 Nov. 1994. Case No: IT-94-1-Tbis-R117 11 November 1999. Disponible en: http:// www.icty.org/case/tadic/4

Ramelli, A. (2011). Jurisprudencia penal internacional aplicable en Colombia. Bogotá: Agencia de Cooperación Internacional, Universidad de los Andes, Embajada de la República Federal de Alemania.

Roxin, C. (2000). Autoría y dominio del hecho en derecho penal. Barcelona: Marcial Pons, Ediciones Jurídicas y Sociales.

Roxin, C. (2006). El dominio de organización como forma independiente de autoría mediata. Revista Penal, 18.

Simon, J. M. (2014). El dominio del hecho macrocriminal. Fundamentos. XXXV Jornadas internacionales de derecho penal. Procesos de paz. Derecho penaly justicia transicional. Bogotá: Universidad Externado de Colombia. 